\title{
Recombinant Cellulase and Cellulosome Systems
}

\author{
Andrew S. Wieczorek, Damien Biot-Pelletier and Vincent J.J. Martin
}

Additional information is available at the end of the chapter

http://dx.doi.org/10.5772/54225

\section{Introduction}

The non-renewable fossil resources currently exploited by the oil and gas industries are the objects of growing concern owing to their finite supply and contribution to global warming. Lignocellulosic biomass is a sustainable alternative to fossil resources, and has the added advantage of not competing with human and animal nutrition. Indeed, lignocellulosic biomass, in particular its main polymer component cellulose, is a potential carbon source for the production of fuels and commodity chemicals in microbes.

Hydrolysis of cellulose polymer molecules to liberate the readily fermentable glucose they contain is a necessary step in their use as feedstock by fermenting organisms. The hydrolysis of cellulose is typically carried out by glycoside hydrolase enzymes termed cellulases, and produced by specialist microorganisms. Organisms that naturally feed on and hydrolyse cellulose are mainly found among filamentous fungi, such as the highly exploited Trichoderma reesei, and obligate anaerobic bacteria such as those of the Clostridium genera. The complete breakdown of cellulose to glucose requires the cooperation of three different types of cellulases. Endoglucanases (EGLs) cleave amorphous cellulose randomly at endo sites to release cellodextrins of various lengths. Cellobiohydrolases (CBHs), on the other hand, are required for the hydrolysis of crystalline cellulose, and release cellobiose by acting at the reducing and non-reducing ends of cellulose strands [1, 2]. Finally, $\beta$-glucosidases (BGLs) produce glucose from the hydrolysis of the cellobiose and cello-oligomers produced by EGLs and CBHs. The three types of enzymes are believed to act synergistically. EGLs cleave at random inside strands, creating termini for $\mathrm{CBHs}$, which in turn contribute to loosening of cellulose crystallinity, making further material available to EGLs [2]. Some cellulases, as well as other proteins involved in cellulose degradation, carry a cellulosebinding domain (CBD) that acts to tether them to their polymeric substrate, and allows them to processively degrade cellulose by crawling along its strands [3]. Certain organisms assemble their cellulases on their cell surface as multi-enzyme complexes termed cellulosomes, notably to enhance synergy between enzymes and promote substrate channelling [4]. 
The bionconversion of cellulose to biofuels or commodity chemicals must proceed through several steps. Following pre-treatment of the biomass, cellulose is hydrolyzed as described in the above paragraph. The glucose liberated by cellulose hydrolysis can then be fed to microbes that produce compounds of interest, for example the yeast Saccharomyces cerevisiae, which ferments it to ethanol. Doing these two steps one after the other is known as sequential hydrolysis and fermentation (SHF). It requires the addition of costly cellulase cocktails separately produced by fungi, and accumulation of glucose during the hydrolysis step leads to end product inhibition. The capital cost of having multiple separate steps, and the time required for sequential conversion processes further reduce the profitability of sequential hydrolysis and fermentation [5]. Simultaneous saccharification and fermentation (SSF) reduces the number of steps and alleviates the end-product inhibition issue, however it still requires the addition of exogenous cellulases [6]. To further reduce costs, a strategy known as consolidated bioprocessing (CBP) has been proposed, which entails the in situ production of cellulases by the fermenting organism. This strategy consolidates enzyme production, hydrolysis and fermentation into a single step. However, CBP requires an organism efficient at both degrading cellulose and fermenting glucose to a single product at high titers. Such an organism does not exist in nature [7]. To overcome this obstacle, two solutions can be envisioned. Efficient cellulose degraders may be engineered to produce chemicals of interest, or alternatively, organisms that natively produce such compounds can be endowed with recombinant cellulase genes.

Thus, the recombinant expression of cellulases, or cellulase systems, enables CBP. It may also be used to reduce exogenous enzyme loads required by SSF, and may have benefits for the production of the cellulase cocktails used in both SHF and SSF. The recombinant and heterologous expression of cellulases in microorganisms may also benefit other industries. The textile industry, for example, uses cellulases to create stonewashing effects on cellulosederived clothing fibres. Use of cellulase-expressing lactic acid bacteria, on the other hand, is of interest for the ensilage of hay fed to livestock. For these reasons, considerable research has been done to engineer organisms that express recombinant cellulases and cellulase systems. The aim of this chapter is to review the progress made in the engineering of such organisms. We first review the production of cellulases expressed as freely secreted or cell surface-anchored enzymes, and divide our discussion based on the types of organisms engineered (yeast, bacteria, then fungi). We then put special emphasis on the production of artificial recombinant cellulosomes and cellulosome-inspired architectures, outlining the different manners in which they can be assembled, and which microorganisms were used to do so.

\section{Cell surface-anchored and secreted recombinant cellulase systems}

The scientific literature is ripe with examples of secreted or surface-anchored recombinant cellulases and cellulase systems expressed in yeast, bacterial and fungal hosts. Most research has focused on a handful of organisms, namely Saccharomyces cerevisiae, the enteric bacteria Escherichia coli and Klebsiella oxytoca, the gram-negative bacterium Zymomonas mobilis, and the cellulolytic fungus Trichoderma reesei. Other species have garnered less attention, yet represent an interest to the field and should not be dismissed. 
This section focuses on work aimed at producing organisms that can efficiently degrade cellulose via the expression of recombinant cellulases. Because the recombinant expression of cellulases was extensively reviewed in a number of publications in the last decade [8-10], the text is centered on the most significant outcomes, and provides an overview of the most recent work.

\subsection{Expression of cellulases in yeast}

Attempts at expressing recombinant cellulases in yeast abound owing to the traditional role of the brewer's yeast Saccharomyces cerevisiae in ethanol production. The use of other yeast species for recombinant expression of cellulases is also discussed in this section, namely species that display interesting metabolic capabilities or stress tolerance characteristics.

\subsubsection{Recombinant cellulase expression in Saccharomyces cerevisiae}

A significant proportion of recombinant cellulase expression studies were performed in yeast, and almost all of that work was done in Saccharomyces cerevisiae. The millennia-old utilization of this organism for ethanol production, its relatively well-studied physiology, and the diversity of readily available tools for its genetic manipulation mean that it is an important candidate for the engineering of a cellulose-degrading ethanologen.

Since the 1990s, numerous cellulases from various bacterial and fungal sources were cloned and expressed in S. cerevisiae, and those have been reviewed elsewhere [8,9]. Over the last thirteen years, a few studies representing significant progress towards the production of a cellulose-fermenting yeast strain were published. Cho and coworkers [11, 12] reported an early example of a recombinant yeast strain that could functionally express several cellulases. Using $\delta$-integration, they inserted multiple copies of two cellulase genes - encoding a bifunctional endo/exo-glucanase and a BGL- into the chromosomes of $S$. cerevisiae. The recombinant organism displayed enhanced growth on cellooligosaccharides when compared to wildtype, and required reduced loads of exogenous cellulases when applied in SSF [12]. However, levels of cellulase expression were deemed low, and did not enable growth and ethanol production using cellulose as the sole carbon source. A later study similarly expressed the three types of cellulases required for cellulose degradation in S. cerevisiae [13]. The EGL and CBH, from Trichoderma reesei, and the BGL, from Aspergillus aculeatus, were co-displayed as $\alpha$-agglutinin fusions on the surface of yeast cells, enabling the liberation of glucose from phosphoric acid swollen cellulose (PASC), and fermentation to ethanol when the cells were pre-grown in rich media. Den Haan and coworkers [14] reported similar accomplishments, co-expressing an EGL from T. reesei and a BGL from the yeast Saccharomycopsis fibuligera in S. cerevisiae. This study was allegedly the first report of direct conversion of cellulose to ethanol by cellulaseexpressing yeast, as it was reported that the engineered strain could grow and produce modest yields of ethanol (1.0 g/L in 192 hours) from PASC in media also containing yeast extract and peptone (YP-PASC). A study published almost simultaneously by the same authors reported the low level expression of CBHs in yeast [15], but expression of these enzymes in the PASCfermenting BGL/EGL background was not reported. 
Following these milestone studies, other groups reported on the expression of cellulases in S. cerevisiae and their use for fermentation of cellulose to ethanol. Jeon and coworkers reported the expression of EgIE from Clostridium thermocellum and BGL1 of S. fibuligera in the budding yeast. The resulting yeast strain could produce ethanol from carboxymethyl cellulose ( $8.56 \mathrm{~g} / \mathrm{L}, 16$ hours), $\beta$-D-glucan $(9.67 \mathrm{~g} / \mathrm{L}, 16$ hours) and PASC (7.16 g/L, 36 hours) after pre-culturing in synthetic galactose medium and extensive washing in minimal media [16]. This was a progress compared to previous studies, in that it did not require yeast extract or peptone to produce ethanol from cellulosic substrates. Another study [17] compared the performance of two recombinant yeast strains in directly converting cellulose to ethanol in YP-PASC medium. A BGL from A. aculeatus was anchored to the cell surface, while an EGL and a CBH were either anchored or secreted. Higher ethanol yields were obtained when all three enzymes were surface-anchored. These results suggested that this configuration enhances the ability of yeast to degrade cellulose and use the resulting sugars in a manner reminiscent of cellulosome-enzyme-microbe complexes (discussed in Section 3).

Direct conversion of cellulose to ethanol poses the problem of finding the optimal ratios of the different types of cellulase. A novel strategy, termed cocktail $\delta$-integration was recently proposed to address this issue [18]. This strategy involves the simultaneous transformation and integration in the yeast chromosomes of BGLs, EGLs and CBHs on a single DNA fragment with a single selection marker. Fragments are designed to carry varying numbers of each cellulase gene. Integrants are then compared in their ability to degrade cellulose, and those with the best ratios can be identified. The procedure can be repeated several times using different selection markers. After three rounds of cocktail $\delta$-integration, Yamada and coworkers [18] were able to generate a strain with twice the activity on PASC, but half the number of cellulase genes than a similar strain generated using a conventional method. These results strongly argue for a successful optimization of cellulase ratio. The activity of the ratio-optimized strain was further improved by making it diploid [19]. The optimized diploid showed an ability to produce ethanol directly from PASC (7.6 g/L in 72 hours) or pretreated rice straw $(7.5 \mathrm{~g} / \mathrm{L})$ in yeast peptone $(\mathrm{YP})$ medium without addition of exogenous enzymes. This was the first report of direct conversion to ethanol of agricultural waste residue without exogenous enzyme addition by recombinant cellulase-expressing yeast [19]. Other strategies used to incorporate enzymes at specific ratios into artificial cellulosomes using yeast consortia are discussed later in this chapter (Section 3.4.1).

Two independent studies gave examples of improved SSF using cellulase-expressing yeast. One study [20] reported the transformation of an industrial strain with a BGL-carrying plasmid, enabling the use of cellobiose as the sole carbon source and its conversion to ethanol, producing $3.3 \mathrm{~g} / \mathrm{L}$ in 48 hours. When supplementing with exogenous cellulases, the strain was shown to produce $20 \mathrm{~g} / \mathrm{L}$ of ethanol from pre-treated corncobs, a yield similar to outcomes obtained with the parent strain supplemented with additional BGL. Another SSF study [21] reported the production of $7.94 \mathrm{~g} / \mathrm{L}$ of ethanol in 24 hours from barley $\beta$-D-glucan using yeast co-displaying a BGL and an EGL from Aspergillus oryzae. 
In recent years, a few thermotolerant enzymes have been expressed in S. cerevisiae. For example, BGL4 from Humicola grisea was recently cloned in the budding yeast [22]. Interestingly, the recombinant enzyme displayed resistance to glucose inhibition in addition to thermotolerance. Others have reported on the expression of thermotolerant cellulases in yeast using a mutagenesis and recombination strategies rather than a discovery approach to further improve stability and activity of the recombinant enzymes [23-25].

Inadequate secretion of cellulases by recombinant yeast is an obstacle to their successful application in an industrial context. To address this issue, a library of approximately 4800 non-essential deletion mutants was systematically transformed with a plasmid carrying an endoglucanase gene from the bacterium C. thermocellum [26]. Mutants were compared in their ability to degrade carboxymethyl cellulose, and 55 of them showed increased activity. The mutants covered a large spectrum of cellular functions, including transcription, translation, phospholipid synthesis, endosome/vacuole function, ER/Golgi function, nitrogen starvation response, and the cytoskeleton. The effect of a subset of these mutations was tested on the level of activity of another cellulase, a BGL from A. aculeatus. Interestingly, five out of the nine mutations tested increased BGL activity in addition to EGL activity, suggesting that certain mutations may increase the secretion level of several cellulases, and potentially all enzymes within a cellulase system [26].

\subsubsection{Recombinant cellulase expression in other yeast species}

While most studies expressing recombinant cellulase systems in yeast have used Saccharomyces cerevisiae, other species, superior to brewer's yeast in some respects, have also been used.

The yeast Scheffersomyces stipitis (formerly Pichia stipitis) is one of the organisms considered for its potential in the bioconversion of lignocellulosic biomass, owing to its native cellulase activity, but foremost to its pentose-fermenting capabilities. Indeed, hemicellulose, the second most abundant sugar polymer of plant cell walls after cellulose, is composed largely of xylose, which S. cerevisiae cannot ferment. S. stipitis, on the other hand, produces the largest yields of ethanol from xylose that have been observed to date [27]. S. stipitis naturally consumes lignocellulosic biomass, therefore cellulase activity, notably $\beta$-glucosidase activity, has been detected in this organism [28], while its genome was found to encode several putative cellulolytic enzymes [29]. Yet, during the development of molecular genetics tools for $S$. stipitis, recombinant cellulases were used as reporters of protein expression [30].

Saccharomyces cerevisiae is generally not viable in conditions of temperature optimal for cellulase activity. Indeed, cellulases from the common cellulolytic microbes $C$. thermocellum and T. reesei are found to lose most of their activity at temperatures below $40^{\circ} \mathrm{C}$ [31], while $S$. cerevisiae grows poorly above $38^{\circ} \mathrm{C}$ [32] and could not so far be engineered to remain productive at temperatures that exceed $42^{\circ} \mathrm{C}$ [33]. In addition, acids are commonly used in the pretreatment of lignocellulosic biomass, while both high temperatures and acidic conditions can be used in preventing contamination during fermentation. For these reasons, 
expression of recombinant cellulase systems has been attempted in a few stress tolerant species of yeast. For example, the thermotolerant Kluyveromyces marxianus was used in a number of SSF studies in which cellulases were added exogenously [34-37]. The strain was subsequently engineered to express three thermostable cellulases, endowing it with the ability to grow at $45^{\circ} \mathrm{C}$ on both cellobiose and carboxymethyl cellulose and to ferment cellobiose to ethanol [38]. The multi-stress tolerant Issatchenka orientalis was also successfully engineered for recombinant cellulase expression. This organism is tolerant to acid, salt and elevated temperature, in addition to being ethanol tolerant, making it a suitable candidate for cellulose bioconversion [39]. Kitagawa and coworkers [40] provided the first report of heterologous gene expression in I. orientalis, isolating and cloning the necessary auxotrophy markers and building a recombinant cassette for the production of A. aculeatus BGL. The engineered strain showed BGL activity and was able to grow and produce ethanol on cellobiose in conditions of elevated temperature, acidity and salinity. SSF trials using this strain achieved measureable ethanol outputs, albeit at lower levels than what was obtained with the parental strain supplemented with exogenous BGL. Still, to achieve similar yields, reduced BGL supplementation was required for the recombinant strain.

\subsection{Expression of cellulases in bacteria}

This section reviews recent research aimed at expressing recombinant cellulases in bacteria. Although the workhouse and longtime protein overproducing Escherichia coli has received significant interest, several other species with specialized functions have also been exploited. These functions include: the ability to assimilate cellulose-derived oligosaccharides, native production of biofuel molecules or organic acids, and thermophilicity.

\subsubsection{Recombinant cellulase expression in enteric bacteria}

The enteric bacterium E. coli has a long history of being used for the expression of recombinant proteins, and numerous tools for the genetic engineering of this organism are readily available. Furthermore, E. coli has among the simplest and cheapest growth requirements. It is thus an attractive canvas for the engineering of a cellulose-utilizing industrial strain. Therefore, it comes to no surprise that studies have reported the heterologous expression of cellulase systems in this organism. Significant advances have also been reported in Klebsiella oxytoca, a bacterium related but superior to E. coli in its native ability to assimilate and use cello- and xylo-oligosaccharides.

Wildtype E. coli and K. oxytoca are not prolific ethanologens and neither have cellulolytic activity. The classical strategy to turn these organisms into ethanol producers is to endow them with an alcohol dehydrogenase and a pyruvate decarboxylase genes from the ethanologenic bacterium Zymomonas mobilis (Section 2.2.2) [41]. It is normally with this background that enteric bacteria have been used for recombinant cellulase expression. Several papers over the course of the last twenty years have reported the engineering of $E$. coli and K. oxytoca in this manner [42-47]. The most advanced examples report the expression 
of the endoglucanase genes celY and celZ from the phytopathogenic bacterium Erwinia chrysanthemi in an ethanologenic K. oxytoca background [46, 47]. This recombinant cellulase system, in conjunction with the native BGL activity of $K$. oxytoca enabled the direct conversion of crystalline cellulose to ethanol with addition of exogenous cellulases [46], while amorphous cellulose could be readily converted to ethanol without exogenous cellulase supplementation [47]. However, as is the case for reports of direct cellulose-toethanol conversion by yeast, these successes depended on the presence of yeast extract and peptone in the fermentation medium.

More recently, a proof-of-concept study by Bokinsky and coworkers [48] reported the expression of complete sets of cellulases and hemicellulases in E. coli for the conversion of lignocellulosic biomass to second-generation biofuels. In this study, a library of EGLs was tested for expression in E. coli, while collections of BGL and xylobiosidases were evaluated for their ability to enable growth of $E$. coli on cellobiose and xylobiose, respectively. The best EGL and BGL genes were introduced into E. coli to generate a cellulose-degrading strain. The best xylobiosidase was similarly combined with a previously identified xylanase to generate a hemicellulose-degrading strain. Growth on ionic liquid-pretreated lignocellulosic feedstock (switchgrass, eucalyptus and yard waste) was demonstrated. Combining both strains allowed enhanced growth on all substrates. The strains were further engineered to express one of three operons for the production of advanced biofuel molecules (fatty acyl ethyl esters, butanol or pinene) from ionic liquid-pretreated switchgrass, achieving modest yields. This study is the first report of a complete cellulose-to-biofuel conversion in bacteria using natural feedstock. Moreover, no exogenous cellulases were added, and all hydrolysis and fermentation experiments in this study were performed in minimal media with cellulose or hemicellulose as the sole carbon source.

\subsubsection{Recombinant cellulase expression in Zymomonas mobilis}

Zymomonas mobilis is an ethanologenic gram-negative bacterium. Unlike S. cerevisiae, it converts glucose to ethanol via the Entner-Doudoroff pathway, enabling ethanol yields that could more closely match theoretical yield values than the classical glycolytic pathway. It is considered superior to brewer's yeast in other respects. Indeed, it has higher tolerance to ethanol, enabling superior yields, which it produces with high productivities [7, 49-55]. Therefore, several reports of recombinant cellulase expression in Z. mobilis have been published [55-59]. Among early reports of recombinant cellulase expression in Z. mobilis [5658], only one succeeded in exporting an EGL to the extracellular milieu using the protein's native signal [56]. In that study, approximately $10 \%$ of the EGL protein was found to be extracellular, while most of the cell-associated activity was found in the periplasm [56]. Recent studies fused recombinant cellulases to native Z. mobilis export signals in an attempt to direct a larger proportion of the enzymes to the extracellular milieu. In one study, a BGL from Ruminococcus albus was fused to the glucose-fructose oxidoreductase and gluconolactonase export signals of Z. mobilis, resulting in the secretion of only $4.7 \%$ and $11.2 \%$ of the protein, respectively. The resulting strain was able to use cellobiose and ferment it to ethanol [55]. A more recent study used two different secretion signals native to 
Z. mobilis, and suggested to use distinct pathways. These endogenous signals were fused to the catalytic domain of two Acidothermus cellulolyticus EGLs, enabling the export of $40 \%-50 \%$ of the recombinant cellulases to either the periplasm or extracellular milieu [59]. This latter study did not report on the ability of the strains to grow on or convert cellulosic substrates. Interestingly, it provided a confirmation to an earlier study that suggested the presence of endogenous cellulase activity in Z. mobilis [60].

\subsubsection{Recombinant cellulase expression in other bacterial hosts}

Other bacterial species with useful industrial properties have been used for the expression of recombinant cellulases. Species such as Clostridium acetobutylicum and Clostridium beijerinckii can be used in the industrial scale production of solvents and biofuels in the acetone-butanol-ethanol (ABE) process [61]. Enthusiasm for biofuels and synthetic biology in recent years has renewed interest for the high yields of solvents, in particular butanol, achieved by these organisms. The classical source of carbon for the ABE process was potato starch, however recent research has been aimed at enabling the use of cellulose, a more sustainable and industrially suitable carbon source, by solventogenic Clostridium. The genome of $C$. acetobutylicum encodes genes for putative cellulosome components, which will be discussed later in this chapter (Section 3.3.2). However, growth of this microbe, while successful on hemicellulose $[62,63]$ has so far not been observed with cellulose as the sole carbon source [64], despite observations that various substrates induce the expression of cellulases in C. acetobutylicum [65, 66]. Therefore, solventogenic Clostridium were engineered to express recombinant cellulases. Most efforts were aimed at reconstituting functional Clostridium cellulolyticum cellulosomes in C. acetobutylicum, but expression of isolated cellulases was also attempted. In an early study, an EGL from the cellulolytic bacteria Clostridium cellulovorans was expressed in C. acetobutylicum [67]. While the resulting strain could degrade carboxymethyl cellulose in Congo Red plate assays, it failed to grow on cellulose as the sole carbon source. Mingardon and coworkers expressed six C. cellulolyticum cellulases in C. acetobutylicum and found that three enzymes, those with lower molecular weights, were successfully secreted [68]. The larger enzymes failed to generate viable clones, or led to accumulation of cellulase protein in the cytoplasm. In a subsequent study, the same group reported the successful secretion of large cellulases by fusing them to sequences of scaffoldins and cellulose binding modules of C. cellulolyticum [69]. The related species $C$. beijerinckii was also used for the heterologous expression of recombinant cellulases. Expression of an EGL from the cellulolytic fungus Neocallimastix patriciarum in C. beijerinckii yielded results that resembled those observed with $C$. acetobutylicum. Indeed, the recombinant $C$. beijerinckii strain displayed cellulolytic activity in Congo Red plate assays, but failed to grow on cellulose. Interestingly, the fungal EGL improved growth and solvent yields of the microbe on lichenan, a polymer of glucose similar to cellulose [70].

Lactic acid bacteria (LAB) have also served as hosts for recombinant cellulase expression. The interest of LAB lies in their potential as silage inocula, probiotics, and industrial lactic acid producers. Several LAB species, including Lactobacillus plantarum and Lactococcus lactis have been engineered for the improved lactic fermentation of forage by expressing cellulose- 
degrading enzymes. Early studies reported the successful expression and secretion of functional EGLs from plasmids [71] or from the chromosome [72] in L. plantarum. Chromosome integration of a Bacillus sp. EGL in L. plantarum was later shown to elicit increased acidification of forage in micro-ensiling experiments [73]. Similarly, L. lactis was transformed with a cellulase gene from the rumen fungus Neocallimastix sp. [74]. The recombinant $L$. lactis strain enhanced the digestibility of forage when used in ensiling experiments. Lactobacilli species L. gasseri and L. johnsonii, natural inhabitants of the mammalian gastrointestinal tract, were also engineered to express a $C$. thermocellum endoglucanase [75]. The aim of this study was to generate probiotics that would facilitate digestion of plant cell walls by monogastric animals, thus alleviating the need for the onerous supplementation of animal feed with exogenous cellulases. The resulting strains displayed cellulase activity on carboxymethyl cellulose, and had characteristics desirable for probiotics. A lactate dehydrogenase-deficient strain of L. plantarum was later engineered to express a $C$. thermocellum EGL, allowing the successful hydrolysis and conversion of barley $\beta$-D-glucan to lactic acid in anaerobic conditions, achieving best yields with addition of exogenous BGL [76].

We have already mentioned the relevance and interest of thermotolerant or thermophilic enzymes for the bioconversion of cellulose. While tools for the genetic engineering of thermophilic bacteria are still in their infancy [77], one example of cellulase expression is found in the thermophile Thermoanaerobacterium saccharolyticum [78]. In this study, development of recombinant protein expression systems used cellulases and other glycoside hydrolases from $C$. thermocellum as test proteins, and cellulase activity was detected.

\subsection{Expression of cellulases in fungi}

Several species of fungi are superior protein secretors, and as such show high potential for the industrial-scale production of enzymes. Not surprisingly, the cellulase cocktails used in industry for the bioconversion of cellulose or for the treatment of textile fibers are typically produced by cellulolytic fungi [79]. The organism most commonly used for this purpose is the filamentous fungus Trichoderma reesei, because of the high titers of cellulase enzymes that it secretes [80]. Recombinant approaches have been applied to enhance the production of native cellulases or to express heterologous cellulolytic enzymes in T. reesei and other fungi.

To increase yields of EGL produced by T. reesei, Miettinen-Oinonen and Suominen reported a strategy whereby the native $c b h 2$ locus was disrupted to redirect the secretory capabilities of the fungus towards other proteins [81]. This CBH-deficient background was transformed with constructs of $T$. reesei EGL genes placed under the control of the strong $c b h 2$ promoter. These modifications, coupled to an increase in EGL copy number, were successful in augmenting the levels of secreted EGL, and in increasing the performance of the T. reeseisecreted enzyme in stonewashing treatment of denim fabric. A follow-up study by the same group tested the effect of promoter swapping, deletion of native enzymes, and copy number increase on the level of $\mathrm{CBH}$ secretion, yielding comparable results [82]. Another approach aimed at increasing the activity of the T. reesei-secreted cellulase cocktail was to fuse an $A$. 
cellulolyticus EGL domain to native $\mathrm{CBH}$ expressed in $T$. reesei. The resulting bi-functional enzyme increased the saccharification yields of T. reesei [83].

Several studies have reported the heterologous expression of thermophilic fungal cellulases in mesophilic fungi, notably T. reesei, Aspergillus oryzae and Humicola insolens (reviewed in [84]). For example, protein variants of the Cel12A enzyme of T. reesei rationally designed for increased thermal stability and activity were expressed in the efficient protein secretor Aspergillus niger [85]. In another study, the cellobiohydrolase Cel7A from T. reesei was expressed in $A$. niger, and mass spectrometry was used to compare N-glycosylation between the recombinant and the native protein. The cellobiohydrolase contained six times more $\mathrm{N}$ linked glycans when expressed in A. niger, and its activity was reduced, underlining the critical effect of post-translation modifications on recombinant cellulases [86]. Recently, a library of EGLs from various fungi were cloned and expressed in A. niger [87]. Both activity and level of expression were compared to that of $\operatorname{TrCel} 5 \mathrm{~A}$, one of the major endoglucanases from $T$. reesei. This screen identified three EGLs, from species Aureobasidium pullulans, Gloeophyllum trabeum and Sporotrichum thermophile with expression levels and hydrolysis performances superior to those of the Trichoderma enzyme [87].

\section{Recombinant cellulosomes}

The degradation of recalcitrant cellulosic substrates into fermentable carbohydrates requires multiple catalytic activities [4]. Many cellulolytic fungi are capable of degrading crystalline cellulose by secreting cocktails of free hydrolytic enzymes [88]. Alternatively, the hydrolysis of cellulosic substrates can be carried out by macromolecular enzyme complexes [4]. The incorporation of enzymes in a larger multi-enzyme complex yields several benefits associated with substrate channeling as well as synergy among neighboring enzymes [89]. Substrate channeling refers to the flow of intermediate metabolites from one reaction to another, where individual catalytic activities are co-localized in a central protein scaffold. In the case of cellulose hydrolysis, longer chain polysaccharides produced by non-processive cellulases become the substrate for processive cellulases, which can produce short chain cellodextrins and cellobiose as primary products. Enzyme synergy results when the sum of individual enzyme activities is augmented by their incorporation in multi-enzyme complexes. From a biotechnological perspective, optimizing the spatial organization of enzymes through co-localization can greatly enhance the channeling of hydrolysis intermediates to enzymes that will use them as substrates. A number of cellulolytic bacteria have evolved to assemble multi-enzyme complexes such as cellulosomes. Cellulosomes have become inspiration for the engineering of recombinant complexes with defined enzyme compositions. For instance, the thermophilic bacterium $C$. thermocellum, which is documented to have one of the most efficient system for cellulose hydrolysis [89], produces one of the most thoroughly studied and well-characterized cellulosomes. The engineering of multiple cellulases into macromolecular cellulolytic complexes is a strategy that has been adopted by a number of research groups in the development of microorganisms that can degrade cellulose and produce commodity chemicals and biofuels. 


\subsection{Nature's building blocks for engineering recombinant cellulosomes}

Cellulosomes are cellulose-degrading protein complexes comprised of a multitude of hydrolytic enzymes with varying catalytic activities that associate with a central scaffold protein [90]. The variability in architecture of cellulosomes from different organisms has been a significant source of inspiration for the engineering of protein scaffolds and multienzyme complexes [91-94]. The assembly of the cellulosome complex is mediated via noncovalent interactions between non-catalytic dockerin and cohesin domains. These domains serve as the building blocks that hold the complex together and dictate its architecture. Two characteristics of a dockerin and cohesin pair determine the specificity of the interaction: the species from which they are derived, as well as the type of interaction. Type 1 and type 2 cohesins from a single organism do not interact with dockerins of the opposite type (e.g. type 1 cohesins do not interact with type 2 dockerins, and vice-versa). In the case of $C$. thermocellum, type 1 dockerins and cohesins mediate the interaction between enzymes and scaffold proteins, while type 2 dockerins and cohesins mediate binding of scaffolds and cell surface anchor proteins. Cellulosomal enzymes carry type 1 dockerin domains which bind any of the nine type 1 cohesin domains found on the central scaffold protein CipA [95]. Cellulosomal scaffolds such as CipA typically contain a CBD that brings the complex in close proximity to the cellulose fibers, allowing the different cellulases to act in synergy on the crystalline substrate. CipA protein also carries a type 2 dockerin domain, which interacts with type 2 cohesins located on cell wall anchor proteins OlpB and SdbA [96, 97]. These anchor proteins ensure the attachment of the complex on the cell surface. In addition, cohesin and dockerin domains derived from different organisms do not bind with one another. Therefore, cohesins and dockerins from different species as well as those of different types have become the building blocks used by researchers to engineer customdesigned recombinant cellulosomes or cellulosome-inspired complexes with precise compositions. The strategies adopted by most researchers in this effort can be divided into three categories discussed in subsequent sections. These include (i) the production of recombinant enzymes and scaffolds in host strains followed by their purification and assembly in vitro (Figure 1A), (ii) the production of all components in a single strain resulting in the in vivo assembly of resulting complexes in the culture supernatant (Figure 1B), and (iii) the surface-tethering of scaffolds towards the in vivo assembly of artificial cellulosomes on the cell surface of the host organism (Figure 1C).

\subsection{In vitro assembly of recombinant cellulosomes}

The assembly of custom-designed cellulosomes initially involved the production of individual components in an organism of choice, followed by their purification and assembly in vitro. Desirable characteristics for a bacteria designed to overexpress individual components include ease of manipulation of the organism, and low endogenous proteolytic activity. Since multiple strains are used to generate individual components, this strategy is not limited to a single organism being used for the production of each recombinant subunit, since further purification and in vitro assembly of the final complex is required (Fig. 1A). 


\section{A}
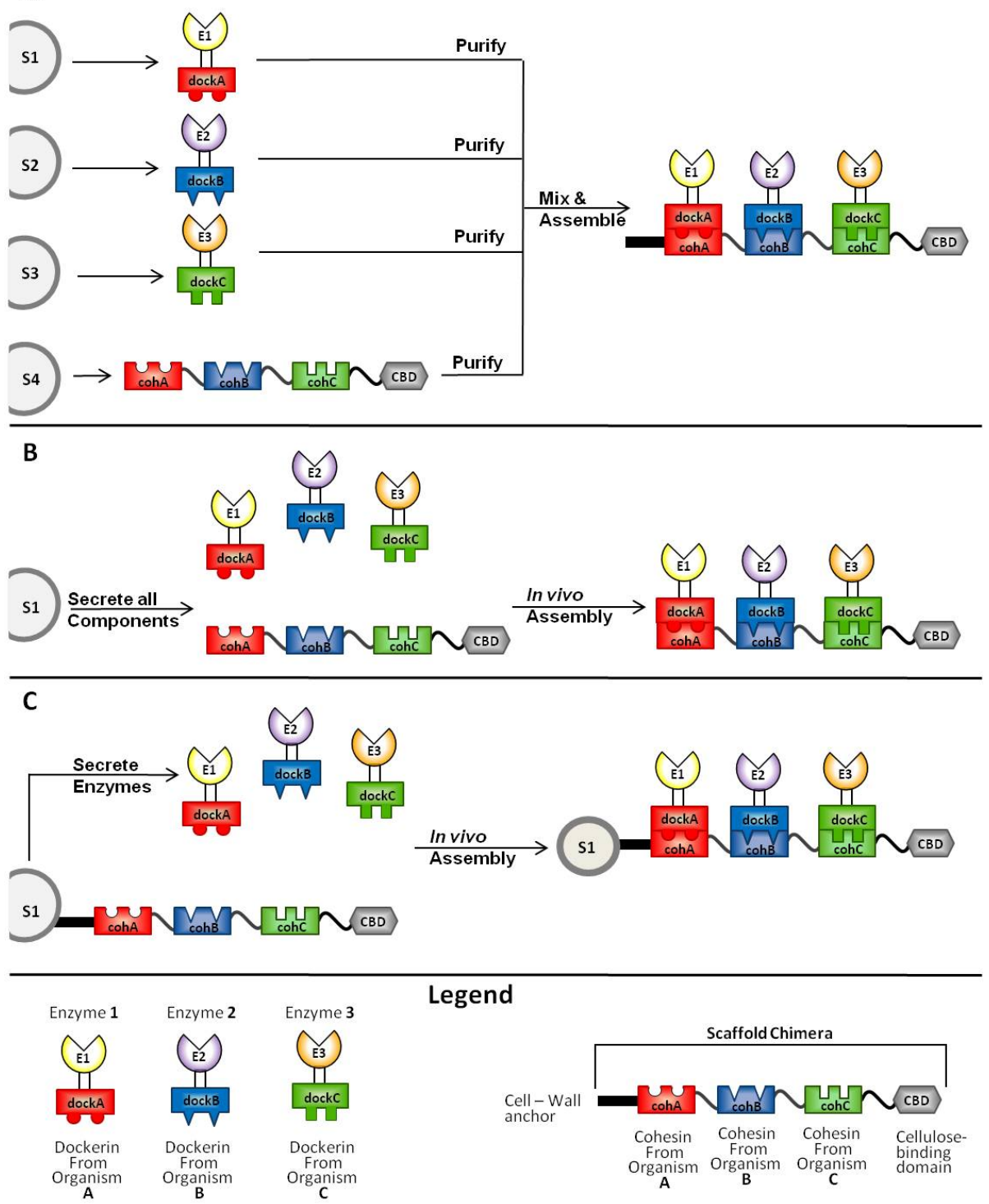

Figure 1. Strategies for the assembly of artificial cellulosome complexes. (A) Enzyme-dockerin fusions and scaffold chimeras are produced by different strains of a host organism (e.g. S1, S2, S3, S4), purified, and subsequently assembled in vitro. (B) Enzymes and scaffold subunits are secreted by a single host organism into the culture supernatant where they self-assemble into cellulosomes in vivo. (C) A host organism tethers a scaffold to its surface while secreting recombinant enzyme-dockerin fusions, resulting in the in vivo assembly of the cellulosome complex on the cell surface. 


\subsubsection{Expression of cellulosome components in E. coli}

Early work on the in vitro assembly of cellulosomes focused mostly on demonstrating the effects of having cellulase enzymes bound to a scaffold on activity towards cellulose. In a study by Kataeva and coworkers, the EGL CelD was shown to bind stoichiometrically with fragments of the CipA scaffold protein, and CelD-CipA complexes showed increased activity on cellulose compared with free CelD enzyme. A major observation was that the activity of the complex was dependent on the presence of a cellulose binding domain (CBD), not necessarily the amount of CelD present. The authors hypothesized that the CBD located on the scaffold protein was either indirectly contributing to the hydrolysis process by optimally positioning CelD to act on the crystalline substrate, or that it was playing a more direct role, participating in the partial decomposition of the substrate and ultimately, allowing access to CelD [98]. A subsequent study by Ciruela and colleagues revealed that the binding of another EGL, CelE, with full length CipA, resulted in the assembly of artificial cellulosomes with increased activity on crystalline cellulose compared to free enzymes [99]. Interestingly, although the CBD of CipA was capable of binding both crystalline and amorphous cellulose, the increase in activity observed when CelE was complexed with CipA was only observed on the former, suggesting the pivotal role of the scaffold-enzyme complex in degrading the crystalline substrate. Both studies conducted by Kataeva and Ciruela involved the incorporation of a single enzyme into artificial cellulosomes. Murashima and coworkers used a truncated version of the C. cellulovorans scaffold protein CbpA (Mini-CbpA) and three enzymes, EngE, EngH, and EngS, for the in vitro assembly of artificial cellulosomes containing combinations of two enzymes [100]. Synergy was affected by both the type and stoichiometric ratios of enzyme used. Optimal combinations of enzymes were determined based on increased activity on crystalline cellulose. In this case, however, the effects of relative enzyme positioning within the complex could not be deduced due to the non-specific binding of each enzyme with any of the two cohesins present on the scaffold. The multiple cellulase activities required to degrade crystalline cellulose and the possibility to optimize their positioning within an artificial cellulosome prompted the construction of recombinant protein scaffolds using cohesins with different specificities.

Initial work describing the construction of chimeric scaffolds was carried out by Fierobe and coworkers, where the fusion of cohesins derived from the cellulosomes of $C$. thermocellum and C. cellulolyticum were used to engineer complexes with dual enzyme activities [101]. The authors engineered a total of four scaffolds that contained two divergent cohesins positioned at various locations relative to the CBD. Two C. cellulolyticum cellulases, CelA and CelF, were engineered to contain either native or C. thermocellum dockerins. All components were over-produced in E. coli, purified and assembled in vitro into threecomponent cellulosomes. The authors once again demonstrated the necessity of the CBD for increased hydrolysis of the cellulose substrate, and observed that the sequential or simultaneous assembly of each component yielded similar activities. Increased synergy, however, was observed when enzymes were positioned adjacent to each other, suggesting a possible mechanism of substrate channeling between catalytic domains. In a subsequent 
effort, Fierobe and colleagues successfully generated a library of 75 different chimeric cellulosomes and tested their activities on both crystalline and less recalcitrant substrates [102]. The enzymes incorporated into the bifunctional complexes consisted of a combination of C. cellulolyticum cellulases CelA, CelC, CelE, CelF, or CelG. Synergy due to enzyme assembly on the chimeric scaffolds was only observed when acting on the more recalcitrant substrates such as Avicel and bacterial microcrystalline cellulose, with less or no synergy observed when acting on the less crystalline substrates bacterial cellulose and PASC. To further augment the synergistic and overall activities of bifunctional artificial cellulosomes, Fierobe and coworkers generated trifunctional cellulosomes [91]. In order to control the relative position of the enzymes within the complexe, a third dockerin-cohesin pair derived from Ruminococcus flavefaciens was used in which the interaction is characterized by both high affinity and lack of cross-reactivity with other cohesin-dockerin pairs. Upon incorporation of three cellulases, the complexes demonstrated significantly higher activity than their bifunctional counterparts. The synergy among the complexed enzymes was also demonstrated.

In an effort to generate artificial cellulosome systems with novel geometries and potentially higher overall activities on cellulose, Mingardon and coworkers constructed chimeric scaffolds and cellulases designed to self-assemble in precise spatial arrangements [92]. A hybrid cellulosome consisted of enzymes targeted to a central scaffold, a covalent cellulosome was generated by covalently fusing all components together in a single polypeptide chain, and three other cellulosomes with novel architectures were engineered as well. Still, the hybrid cellulosome, which more closely resembled traditional cellulosome architectures, demonstrated significantly higher activity than all others [92]. Some other notable observations were that the least effective cellulosome contained the most CBDs and that in certain architectures, cohesin-dockerin pairs could dissociate, most probably due to conformational strain.

Cellulosic biomass is mostly composed of lignin and hemicellulose in addition to cellulose. To bestow hemicellulase activity upon engineered cellulosomes, Morais and colleagues intergraded two xylanases as well as a xylose binding domain to a scaffold containing three divergent cohesins from Acetivibrio cellulolyticus, C. thermocellum, and R. flavefaciens [103]. The assembled complexes demonstrated a 1.5 fold increase in activity on hatched wheat straw when compared with the free enzyme mixtures, and the authors attributed this to substrate targeting by the xylose binding domain as well as to the proximity of the enzymes within the complex [103]. This system was further improved in a subsequent study whereby another dockerin-cohesin pair derived from Bacteriodes cellulosolvens was incorporated resulting in a four component artificial cellulosome that could accomodate two EGLs and two xylanases [104]. An overall 2.4-fold increase in activity on hatched wheat straw was observed compared with the free enzyme mixtures.

\subsubsection{Expression of cellulosome components in B. subtilis}

While E. coli remains an attractive host for the production of enzymes and scaffolds the presence of endogenous proteases can lead to the degradation of desired proteins. Another 
attractive host towards the production of recombinant cellulosomes is B. subtilis, since it can be easily genetically manipulated, is characterized by fast growth, and is an efficient protein secretor. A strain of B. subtilis deficient in eight major extracellular proteases, B. subtilis WB800, was engineered and used as a host for the production and secretion of $C$. cellulovorans EngE since this enzyme was shown to be partially degraded in E. coli [105]. Murashima and colleagues were successful in using this protease-deficient strain to produce EngE, and subsequent incubation with scaffold Mini-CbpA, which contains a CBD as well as two cohesins, resulted in assembly of an enzyme-scaffold complex capable of binding cellulose [105].

\subsection{In vivo secretion and assembly of recombinant cellulosomes}

The overexpression and purification of individual scaffolds and enzymes towards the assembly of artificial cellulosomes poses extra costs and steps towards cellulose hydrolysis. Rather, the development of a CBP-capable organism would require the production, secretion and in vivo assembly of artificial cellulosomes in the extracellular space (Fig. 1B).

\subsubsection{Secretion of recombinant cellulosomes by B. subtilis}

Initial work began as an extension of Murashima and colleagues' work employing B. subtilis WB800 as a host for heterologous production of all components. Cho and colleagues constructed an expression cassette encoding both Mini-CbpA and EngE on a single vector which was established in B. subtilis WB800 [106]. The result was the secretion and subsequent assembly of both enzyme and scaffold components into an artificial cellulosome complex which was localized in the supernatant. This study was the first report of the in vivo assembly of artificial cellulosomes by a single organism, although the activity of this strain against cellulosic substrates was not verified. A study by Arai and colleagues used a different approach towards the in vivo assembly of recombinant cellulosomes. In this case, three strains of $B$. subtilis WB800 were engineered to secrete either EngB, XynB, or MiniCbpA into the culture supernatant [107]. By co-culturing enzyme and scaffold producing strains, complexes formed in the supernatant and were characterized by the appropriate enzymatic activity. This provided a novel method for assembling complexes in vivo based on intercellular complementation.

\subsubsection{Secretion of recombinant cellulosomes by C. acetobutylicum}

C. acetobutylicum is an organism which has been employed in the production of a number of acids and solvents including acetone, butanol, and ethanol. The potential to engineer this organism to degrade cellulose as a cheap and abundant carbon source has garnered significant attention in the past decade. Interestingly, this bacterium is not cellulolytic, however investigation of its genome sequence reveals a cellulosomal gene cluster encoding a number of hydrolytic enzymes as well as a scaffold protein CipA [64, 108]. Sabathe and colleagues were successful in engineering C. acetobutylicum to secrete and assemble a functional minicellulosome in vivo [109]. Since CipA had been previously demonstrated to 
not be secreted in this organism, the authors replaced the original signal peptide with that of the C. cellulolyticum scaffold protein CipC. Overexpression and secretion of a truncated version of CipA containing two cohesin domains and a CBD resulted in its binding with endogenous cellulase Cel48A, and formation of a secreted cellulosome in vivo [109]. In analyzing the activity of the recombinant cellulosome on Avicel, bacterial cellulose, PASC and carboxymethyl cellulose, no detectable activity was observed when using the crystalline substrates, as is the case for native $C$. acetobutylicum. Low levels of activity were observed on carboxymethyl cellulose and PASC, however such levels did not exceed those demonstrated by the native cellulosome. A next logical step was to produce artificial scaffold chimeras in this organism, capable of binding enzymes at very precise locations via divergent cohesin domains derived from different bacterial species. Perret and colleagues first engineered this organism to produce and secrete scaffold miniCipC1 which is a truncated form of $C$. cellulolyticum scaffold CipC, and subsequently generated chimeric scaffold Scaf3 which contains cohesins from both C. cellulolyticum and C. thermocellum, as well as a CBD [93]. After visualizing the chimeric scaffold using SDS-PAGE, the protein was blotted on a nitrocellulose membrane and was subsequently shown to bind both Cel48 and Cel9 containing a dockerin from C. cellulolyticum, as well as Cel9 with a dockerin from C. thermocellum.

\subsection{In vivo surface-anchoring of recombinant cellulosomes}

The architecture of the cellulosome establishes proximal and synergistic effects of enzymes within the complex when associated with the substrate [95, 110, 111]. In natural and recombinant systems, these synergistic effects are further augmented by an extra level of synergy resulting from the cellulosome's association with the surface of cells, yielding cellulose-enzyme-microbe (CEM) ternary complexes [89, 112-118]. CEM ternary complexes benefit from the effects of microbe-enzyme synergy, ultimately limiting the escape of hydrolysis products and enzymes, increasing access to substrate hydrolysis products, minimizing the distance products must diffuse before cellular uptake occurs, concentrating enzymes at the substrate surface, protecting hydrolytic enzymes from proteases and thermal degradation, as well as optimizing the chemical environment at the substrate-microbe interface [89, 112-116]. In several cellulosome-producing bacteria, including C. thermocellum, the cellulosome is anchored to the surface of cells, resulting in one of the most efficient systems for bacterial cellulose hydrolysis $[4,116]$. In an effort to mimic such a system, microbial engineers have adopted this strategy as a next logical step towards the improvement of recombinant cellulosome systems with the ultimate goal of increasing the efficiency of the bioconversion process.

\subsubsection{Anchoring recombinant cellulosomes on the cell surface of S. cerevisiae}

Much interest towards the development of a CBP-capable organism comes from a desire to generate biofuels such as ethanol from cheap and abundant substrates. Therefore, much attention has been directed towards engineering cellulosome systems in ethanologenic organisms such as S. cerevisiae. Lily and colleagues were successful in targeting hybrid 
scaffold Scaf3p to the cell surface of $S$. cerevisiae by fusing it with the glycosyl phosphatidylinositol (GPI) signal peptide of the Cwp2 protein for linking to the $\beta-1,6$ glucan of the yeast cell wall [119]. The scaffold contained two divergent cohesins from $C$. thermocellum and C. cellulolyticum as well as a CBD. Microsocopy revealed that the CBD was functional in adhering cells to filter paper, and the successful targeting of a Cel5a-dockerin fusion to the scaffold confirmed functionality of the cohesin modules. The ability to generate scaffold chimeras using non-cohesin modules was established by Ito and colleagues [120]. This research group generated artificial scaffolds by fusing the $\mathrm{Z}$ domain of Staphylococcus aureus Protein A with a cohesin from the $C$. cellulovorans cellulosome and displayed them on the cell surface [120]. The scaffold chimeras were engineered to contain two $Z$ domains as well as two cohesins for precisely targeting different enzymes to the cell surface. The authors fused two enzymes, EGII and BGLI, to either a dockerin domain or Fc domain, which successfully targeted the enzymes to the cohesin and $\mathrm{Z}$ domains, respectively [120]. Hydrolysis experiments on $\beta$-glucan revealed that co-displaying EGII-FC and BGL-dock resulted in cells capable of degrading this soluble cellulosic substrate, but due to lack of a $\mathrm{CBD}$ on the engineered scaffold, this strain would most likely be inefficient at hydrolyzing more recalcitrant cellulosic substrates. A more direct approach to ethanol production was adopted by Tsai and coworkers, where yeast strains were engineered to display a trimeric scaffold containing three divergent cohesins from $C$. thermocellum, C. cellulolyticum and $R$. flavefaciens as well as a CBD [121]. Three enzymes, C. thermocellum CelA, and C. cellulolyticum CelE and CelG were overproduced in E. coli and successfully targeted to corresponding cohesin domains on the scaffold by fusion with appropriate dockerin domains, resulting in the surface-display of trifunctional cellulosomes. The anchor system used in this study consisted of displaying the Aga1 protein which interacted with the Aga2 protein fused with the scaffold. Replacing endoglucanase CelG with $C$. thermocellum $\beta$-glucosidase BglA resulted in significant increases in glucose liberation from PASC, and the resulting strain was capable of directly producing ethanol from this substrate. Incubating cells in the presence of PASC resulted in ethanol production that corresponds to $95 \%$ of the theoretically attainable ethanol yield. The authors also observed no accumulation of glucose in the medium during the fermentation assays, suggesting that the released glucose was immediately taken up by cells during the SSF process [121].

The production of both enzymes and scaffold in a single yeast strain was achieved by Wen and colleagues [94]. The scaffold contained three cohesins as well as a CBD and was successfully displayed by use of the $\alpha$-agglutinin adhesion receptor. In vivo secretion of an $\mathrm{EGL}, \mathrm{CBH}$, and BGL resulted in the assembly of tetrameric complexes, and the resulting yeast strain was capable of directly converting PASC to ethanol at a yield of $1.8 \mathrm{~g} / \mathrm{L}$. Interestingly, the authors also observed that when Bgl1 was positioned within the complex, in close proximity to EGII and CBHII, increased activity was observed, most probably due to removal of the cellobiose at the cell surface which may have been inhibiting EGII and CBHII. In comparison with the work by Tsai and colleagues, this represented the first report of producing and assembling a trifunctional cellulosome on the cell surface by the in vivo production of all components. The relatively low levels of EGII and Bgl1 produced by this strain, however, suggested that burdening the secretion machinery of the organism was a 
potential bottleneck. To address this issue, the Chen group adopted a different approach towards the in vivo assembly of trifunctional complexes on the cell surface which entailed intercellular complementation by a yeast consortium [122]. In this case, one strain produced a trifunctional scaffold containing three divergent cohesins and a CBD, while each of three other strains produced an exoglucanase, EGL, or BGL which were targeted to specific sites on the artificial scaffold by fusion with corresponding dockerin domains. The authors also reported that an optimal ratio of each strain within the consortium resulted in two-fold increase in ethanol production when compared with a consortium containing equal proportions of each strain.

\subsubsection{Anchoring recombinant cellulosomes on the cell surface of L. lactis}

While of the attention to the engineering of organisms to display artificial cellulosomes has been directed towards ethanol-producing microbes, the metabolic diversity among microorganisms suggests that such a strategy can be implemented towards the production of other commodity chemicals including organic acids. In an effort to assemble cellulosomeinspired multi-enzyme complexes on the surface of a bacterium, Wieczorek and Martin engineered a strain of $L$. lactis to anchor mini-scaffolds on the cell surface [123]. While several bacterial species non-covalently anchor cellulosomes to the cell surface by means of S-layer homologous domains, other organisms such as $R$. flavefaciens display cellulosomes by covalently anchoring them to the cell wall by sortase. Therefore, the authors in this study fused fragments of $C$. thermocellum CipA scaffold with a C-terminal LPXTG-containing anchor motif from Streptococcus pyogenes M6 protein, resulting in their successful surface-display. By fusing the scaffolds with the export-specific reporter, S.aureus nuclease NucA, the authors were able to easily detect them in the extracellular medium. Fusion of $E$. coli $\beta$-glucuronidase UidA with the dockerin from major $C$. thermocellum cellulosomal enzyme CelS, resulted in its successful targeting to the surface-displayed scaffolds. While the assembled complexes were not cellulolytic, the investigation yielded insights into parameters affecting secretion and anchoring of the recombinant scaffolds, including the observation that scaffold size was not a significant bottleneck in display efficiency. The strain used was deficient in its major extracellular housekeeping protease HtrA, which has been demonstrated to be responsible for the degradation of secreted recombinant proteins. In a subsequent study, the authors fused type 1 and type 2 cohesins to generate scaffold chimeras capable of binding UidA and E. coli $\beta$ galactosidase LacZ fused with type 1 and type 2 dockerins (unpublished data). This system yielded novel insights into the assembly of displayed complexes, suggesting that enzyme size and position relative to the cell surface may play a role in determining the overall net enzymatic profile of the displayed complexes.

\subsubsection{Anchoring recombinant cellulosomes on the cell surface of B. subtilis}

The interest in B. subtilis as a potential candidate for the consolidated bioprocessing of cellulosic substrates into chemicals and fuels resulted in the development of recombinant cellulosome systems in this organism. The attractiveness of this host is compounded by several characteristics including its ability to metabolize $C_{5}$ and $C_{6}$ sugars as well as its natural ability to uptake long-chain cellodextrins. Anderson and colleagues used a system 
similar to the Martin group's by employing the sortase-mediated anchoring of proteins on the cell surface [124]. This group initially demonstrated proof of concept by displaying a single enzyme, Cel8A, and subsequently went on to display cohesin domains capable of interacting with an appropriate Cel8A-dockerin fusion. It was observed that proteolytic degradation of the displayed enzymes resulted in an $80 \%$ decrease in activity after only 6 hours, an effect hypothesized to result from the presence of the extracellular housekeeping protease WprA. Inserting this system into a WprA- strain resulted in a significant reduction in the observed proteolysis of the enzymes. The most complex artificial cellulosome generated by this group included a surface-anchored chimeric scaffold containing three divergent cohesins and a CBD. Incubation of cells with enzyme-dockerin fusions purified from $E$. coli resulted in the assembly of functional minicellulosomes on the cell surface. Soon afterwards, the Zhang group reported the engineering of a scaffold-displaying B. subtilis strain capable of binding three enzymes and the subsequent assembly of an artificial cellulosome on the cell surface [125]. These authors investigated the effect of the CEM ternary complex by comparing a cell-bound artificial cellulosome, a cell-free artificial cellulosome, and a commercial fungal cellulose mixture. Comparative enzyme assays were conducted on the recalcitrant substrate Avicel, as well as amorphous cellulose. When comparing the activity of cell-bound cellulosomes vs. cell-free cellulosomes, a larger significant increase in CEM synergy on Avicel as opposed to amorphous cellulose was observed in the cell-displayed constructs. The authors suggest this effect to be due to larger product inhibition at the boundary layer when active on crystalline cellulose. Since EGL demonstrates higher hydrolysis activity on amorphous cellulose, and $\mathrm{CBH}$ is more sensitive to product inhibition, the observed results suggest that the benefits of anchoring cellulosomes on the cell surface are a necessary component of a CBP-capable organism. In Table 1, successfully generated recombinant cellulosome components are listed according to host organism and assembly strategy.

\begin{tabular}{|c|c|c|c|c|c|c|}
\hline Strategy & $\begin{array}{l}\text { Host } \\
\text { Microbe }\end{array}$ & $\begin{array}{l}\text { \#* Divergent } \\
\text { Cohesins } \\
\text { on scaffold }\end{array}$ & \#* Enzymes & Scaffolds ${ }^{* *}$ & $\begin{array}{l}\text { Enzymes } \\
\text { Targeted } \\
\text { to Scaffold } \\
\end{array}$ & Ref \\
\hline \multirow[t]{8}{*}{$\begin{array}{l}\text { In vitro } \\
\text { assembly }\end{array}$} & \multirow[t]{8}{*}{ E. coli } & 1 & 2 & $\begin{array}{l}\text { CipA } \\
\text { (cohth) }\end{array}$ & Cel D & [98] \\
\hline & & 1 & 2 & $\begin{array}{l}\text { CipA } \\
\text { (cohth) }\end{array}$ & Cel E & [99] \\
\hline & & 1 & 2 & $\begin{array}{l}\text { Mini-CbpA } \\
\left({ }^{(}{ }^{-} h_{c v}\right)\end{array}$ & Cel E, H, S & [100] \\
\hline & & 2 & 2 & Scaf1-4 & Cel A, F & [101] \\
\hline & & 2 & 2 & $\begin{array}{l}\left(\operatorname{coh}_{\mathrm{th}} / \mathrm{coh}_{\mathrm{cl}}\right) \\
\text { Scaf1-5 }\end{array}$ & $\begin{array}{l}\text { Cel A, C, E, F, } \\
\text { G }\end{array}$ & [102] \\
\hline & & 3 & 3 & $\begin{array}{l}\text { (cohth/ cohcl) } \\
\text { Scaf6 }\end{array}$ & $\begin{array}{l}\text { Cel A, C, E, F, } \\
\text { G }\end{array}$ & [91] \\
\hline & & 3 & 3 & $\begin{array}{l}\left.\text { (cohth / coh } / \text { coh }{ }_{\text {rf }}\right) \\
\text { Scaf3, Scaf6 }\end{array}$ & Cel F, G & [92] \\
\hline & & 3 & 3 & $\left(\operatorname{coh}_{t h} / \operatorname{coh}_{\mathrm{cl}} / \mathrm{coh}_{\mathrm{rf}}\right)$ & Cel 5, Xyn10, & [103] \\
\hline
\end{tabular}




\begin{tabular}{|c|c|c|c|c|c|c|}
\hline Strategy & $\begin{array}{l}\text { Host } \\
\text { Microbe }\end{array}$ & $\begin{array}{l}\#^{*} \text { Divergent } \\
\text { Cohesins } \\
\text { on scaffold }\end{array}$ & \#* Enzymes & Scaffolds ${ }^{* *}$ & $\begin{array}{l}\text { Enzymes } \\
\text { Targeted } \\
\text { to Scaffold } \\
\end{array}$ & Ref \\
\hline & & 4 & 4 & $\begin{array}{l}\text { ScafATF } \\
\text { (cohac / cohth/ cohrf) } \\
\text { Scaf-BTFA } \\
\text { (cohac / cohth/ } \\
\text { cohrf / cohbc) }\end{array}$ & $\begin{array}{l}11 \\
\text { Cel 5, 45, Xyn } \\
10,11\end{array}$ & [104] \\
\hline & $\begin{array}{l}\text { B. subtilis } \\
\mathcal{E} \\
\text { E. coli }\end{array}$ & 1 & 1 & $\begin{array}{l}\text { Mini-CbpA } \\
\left(\text { coh }_{\mathrm{cv}}\right)\end{array}$ & Eng B & [105] \\
\hline \multirow{4}{*}{$\begin{array}{l}\text { In vivo } \\
\text { assembly } \\
\text { secreted }\end{array}$} & B. subtilis & 1 & 1 & $\begin{array}{l}\text { Mini-CbpA } \\
\left(\text { coh }_{\mathrm{cv}}\right)\end{array}$ & Eng B & [106] \\
\hline & & 1 & 1 & $\begin{array}{l}\text { Mini-CbpA } \\
\left(\text { coh }_{\mathrm{cv}}\right)\end{array}$ & XynB / EngB & [107] \\
\hline & $\begin{array}{l}\text { C. Aceto- } \\
\text { butylicum }\end{array}$ & 1 & 1 & $\begin{array}{l}\text { Mini-CipA } \\
\left.\text { (coh }{ }_{c a}\right)\end{array}$ & Cel 48A & $\begin{array}{l}{[109]} \\
{[93]}\end{array}$ \\
\hline & & 1 & 1 & $\begin{array}{l}\text { Scaf3 } \\
\left(\text { cohcl }_{\text {c }} \text { cohth }\right)\end{array}$ & Cel 48F, 9E & \\
\hline \multirow{8}{*}{$\begin{array}{l}\text { In vivo } \\
\text { assembly } \\
\text { anchored }\end{array}$} & $\begin{array}{l}\text { S. } \\
\text { cerevisiae }\end{array}$ & 1 & 3 & $\begin{array}{l}\text { CipA3 } \\
\text { (cohth) }\end{array}$ & $\begin{array}{l}\text { EGII, CBHII, } \\
\text { BGLI }\end{array}$ & $\begin{array}{l}{[121]} \\
{[119]}\end{array}$ \\
\hline & & 2 & 1 & $\begin{array}{l}\text { Scaf3p } \\
\left(\text { cohcl }_{\text {c }} \text { cohth }\right)\end{array}$ & GFP, Cel5A & $\begin{array}{l}{[120]} \\
{[121]}\end{array}$ \\
\hline & & 2 & 4 & $\begin{array}{l}\text { ZZ-cohcoh } \\
\text { (Z domain / coh } \mathrm{cv})\end{array}$ & EGII, BGLI & [122] \\
\hline & & 3 & 3 & $\begin{array}{l}\text { Scaf-ctf } \\
\text { (cohth / cohcl / cohrf) }\end{array}$ & Cel E, A, G & \\
\hline & & 3 & 3 & 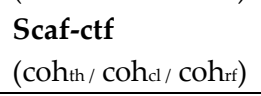 & $\begin{array}{l}\text { Cel E, A, } \\
\text { CBHII, Bgl1 }\end{array}$ & \\
\hline & L. lactis & 1 & 2 & $\begin{array}{l}\text { CipA } A_{\text {frags }} \\
\text { ( cohth) }\end{array}$ & UidA & [123] \\
\hline & B. subtilis & 3 & 3 & $\begin{array}{l}\text { Scaf } \\
\left(\operatorname{coh}_{t h} / \operatorname{coh}_{\mathrm{cl}} / \operatorname{coh}_{\mathrm{rf}}\right)\end{array}$ & Cel8A, 9E, 9G & $\begin{array}{l}{[124]} \\
{[125]}\end{array}$ \\
\hline & & 1 & 3 & $\begin{array}{l}\text { Mini-CipA } \\
\text { (cohth) }\end{array}$ & Cel5, 9, 48 & \\
\hline
\end{tabular}

${ }^{*}$ Corresponds to complexes containing the largest number o divergent cohesins and integrated enzymes.

${ }^{* *}$ Scaffolds listed are containing the largest number of cohesin modules from that study. Names in parenthesis correspond to types of cohesins included in the most complex scaffolds. Coh: cohesin domain. Subscript indicates organism of origin: th (C. thermocellum), $\mathrm{cv}$ (C. cellulovorans), $\mathrm{cl}$ (C. cellulolyticum), $\mathrm{rf}$ ( $R$. flavefaciens), ac (A. cellulolyticum), bc (B. cellulosolvens). Z domains: S. aureus Protein A binding domain.

Table 1. Strategies, organisms and successfully assembled recombinant cellulosomes 


\section{Conclusion}

Recent decades have yielded significant advances in the engineering of non-cellulolytic organisms towards the degradation of cellulosic substrates into fermentable sugars. The recombinant production of cellulases is both a necessary and effective means to both characterize and utilize non-native enzymes in a host organism of choice. In addition, the recalcitrance of crystalline cellulose and complexity of hemicellulose requires multiple enzymes working together to fully achieve this bioconversion process. The potential of custom-designed recombinant cellulosomes to optimize ratio and positioning of enzymes within artificial complexes contribute to this goal. Still, significant advances are necessary in order for the cost-effective transformation of cellulose into valuable commodity chemicals such as bioethanol, non-biofuel hydrocarbons, and organic acids to become an industrial standard. For example, of significant importance is the optimizing of secretion and anchoring mechanisms in host organisms, two factors which can prove to be bottlenecks in the engineering process. Indeed, the native metabolic diversity of microbes designed to utilize cellulose as an energy source, as well as the advent of synthetic biology through which non-native and novel pathways can be introduced into these organisms, suggest that the bioconversion of cellulosic substrates into valuable chemicals is not so far from reach. Constructing more efficient recombinant cellulases, as well as the assembly of cellulosomes with complex architectures inspired by bacteria such as R. Flavifaciens and A. cellulolyticus, are possible avenues to explore in this field. With the inevitable depletion of reserves of conventional energy sources such as petroleum and other fossil fuels, it becomes more evident that cellulosic biomass is not only an attractive source for the production of alternative fuel sources, but may soon become a necessary one.

\section{Author details}

Andrew S. Wieczorek, Damien Biot-Pelletier and Vincent J.J. Martin *

Center for Structural and Functional Genomics, Concordia University, Montréal QC, Canada

\section{References}

[1] Klesov A. Biochemistry and enzymology of cellulose hydrolysis. Biokhimiya. 1991;55(1) 295-318.

[2] Teeri T. Crystalline cellulose degradation: new insights into the function of cellobiohydrolases. Trends Biotechnol. 1997;15(5) 160-167.

[3] Watanabe H, Tokuda G. Cellulolytic systems in insects. Annu Rev Entomol. 2010;55 609-632.

[4] Bayer EA, Belaich JP, Shoham Y, Lamed R. The cellulosomes: multienzyme machines for degradation of plant cell wall polysaccharides. Annu Rev Microbiol. 2004;58 521554 .

\footnotetext{
${ }^{*}$ Corresponding Author
} 
[5] Chang T, Yao S. Thermophilic, lignocellulolytic bacteria for ethanol production: current state and perspectives. Appl Microbiol Biotechnol. 2011;92(1) 13-27.

[6] Philippidis GP, Smith TK, Wyman CE. Study of the enzymatic hydrolysis of cellulose for production of fuel ethanol by the simultaneous saccharification and fermentation process. Biotechnol Bioeng. 1993;41(9) 846-853.

[7] Lynd L. Overview and evaluation of fuel ethanol from cellulosic biomass: technology, economics, the environment, and policy. Annu Rev Energy Environ. 1996;21 403-465.

[8] Lynd LR, Weimer PJ, van Zyl WH, Pretorius IS. Microbial cellulose utilization: fundamentals and biotechnology. Microbiol Mol Biol Rev. 2002;66(3) 506-577.

[9] Lynd LR, van Zyl WH, McBride JE, Laser M. Consolidated bioprocessing of cellulosic biomass: an update. Curr Opin Biotechnol. 2005;16(5) 577-583.

[10] French CE. Synthetic biology and biomass conversion: a match made in heaven? J R Soc Interface. 2009;6 Suppl 4:S547-558.

[11] Cho K, Yoo Y, Kang H. $\delta$-integration of endo/exo-glucanase and $\beta$-glucosidase genes into the yeast chromosomes for direct conversion of cellulose to ethanol. Enzyme Microb Technol. 1999;25(1-2) 23-30.

[12] Cho KM, Yoo YJ. Novel SSF process for ethanol production from microcrystalline cellulose using deltaintegrated recombinant yeast, Saccharomyces cerevisiae L2612 delta GC. J Microbiol Biotechnol. 1999;9(3) 340-345.

[13] Fujita Y, Ito J, Ueda M, Fukuda H, Kondo A. Synergistic saccharification, and direct fermentation to ethanol, of amorphous cellulose by use of an engineered yeast strain codisplaying three types of cellulolytic enzyme. Appl Environ Microbiol. 2004;70(2) 1207-1212.

[14] Den Haan R, Rose SH, Lynd LR, van Zyl WH. Hydrolysis and fermentation of amorphous cellulose by recombinant Saccharomyces cerevisiae. Metab Eng. 2007;9(1) 8794.

[15] Den Haan R, McBride JE, La Grange DC, Lynd LR, Van Zyl W, H. Funtional expresson of cellobiohydrolases in Saccharomyces cerevisiae towards one-step conversion of cellulose to ethanol. Enzyme Microb Technol. 2007;40(5) 1291-1299.

[16] Jeon E, Hyeon JE, Suh DJ, Suh YW, Kim SW, Song KH, et al. Production of cellulosic ethanol in Saccharomyces cerevisiae heterologous expressing Clostridium thermocellum endoglucanase and Saccharomycopsis fibuligera beta-glucosidase genes. Mol Cells. 2009;28(4) 369-673.

[17] Yanase S, Yamada R, Kaneko S, Noda H, Hasunuma T, Tanaka T, et al. Ethanol production from cellulosic materials using cellulase-expressing yeast. Biotechnol J. 2010;5(5) 449-55.

[18] Yamada R, Taniguchi N, Tanaka T, Ogino C, Fukuda H, Kondo A. Cocktail deltaintegration: a novel method to construct cellulolytic enzyme expression ratio-optimized yeast strains. Microb Cell Fact. 2010;9(32) http://www.microbialcellfactories.com/content/9/1/32.

[19] Yamada R, Taniguchi N, Tanaka T, Ogino C, Fukuda H, Kondo A. Direct ethanol production from cellulosic materials using a diploid strain of Saccharomyces cerevisiae with optimized cellulase expression. Biotechnol Biofuels. 2011;4:8 
http://www.biotechnologyforbiofuels.com/content/4/1/8

[20] Shen Y, Zhang Y, Ma T, Bao X, Du F, Zhuang G, et al. Simultaneous saccharification and fermentation of acid-pretreated corncobs with a recombinant Saccharomyces cerevisiae expressing beta-glucosidase. Bioresour Technol. 2008;99(11) 5099-5103.

[21] Kotaka A, Bando H, Kaya M, Kato-Murai M, Kuroda K, Sahara H, et al. Direct ethanol production from barley beta-glucan by sake yeast displaying Aspergillus oryzae betaglucosidase and endoglucanase. J Biosci Bioeng. 2008;105(6) 622-627.

[22] Benoliel B, Poças-Fonseca MJ, Torres FA, de Moraes LM. Expression of a glucosetolerant beta-glucosidase from Humicola grisea var. thermoidea in Saccharomyces cerevisiae. Appl Biochem Biotechnol. 2010;160(7) 2036-2044.

[23] Heinzelman P, Snow CD, Wu I, Nguyen C, Villalobos A, Govindarajan S, et al. A family of thermostable fungal cellulases created by structure-guided recombination. Proc Natl Acad Sci U S A. 2009;106(14) 5610-5615.

[24] Heinzelman P, Snow CD, Smith MA, Yu X, Kannan A, Boulware K, et al. SCHEMA recombination of a fungal cellulase uncovers a single mutation that contributes markedly to stability. J Biol Chem. 2009;284(39) 26229-26233.

[25] Voutilainen SP, Murray PG, Tuohy MG, Koivula A. Expression of Talaromyces emersonii cellobiohydrolase Cel7A in Saccharomyces cerevisiae and rational mutagenesis to improve its thermostability and activity. Protein Eng Des Sel. 2010;23(2) 69-79.

[26] Kitagawa T, Kohda K, Tokuhiro K, Hoshida H, Akada R, Takahashi H, et al. Identification of genes that enhance cellulase protein production in yeast. J Biotechnol. 2011;151(2) 194-203.

[27] du Preez JC, van Driessel B, Prior BA. Ethanol tolerance of Pichia stipitis and Candida shehatae strains in fed-batch cultures at controlled low dissolved-oxygen levels. Appl Microbiol Biotechnol. 1989;30:53-58.

[28] Lee JW, Rodrigues RC, Jeffries TW. Simultaneous saccharification and ethanol fermentation of oxalic acid pretreated corncob assessed with response surface methodology. Bioresour Technol. 2009;100(24) 6307-6311.

[29] Jeffries TW, Grigoriev IV, Grimwood J, Laplaza JM, Aerts A, Salamov A, et al. Genome sequence of the lignocellulose-bioconverting and xylose-fermenting yeast Pichia stipitis. Nat Biotechnol. 2007;25(3) 319-326.

[30] Piontek M, Hagedorn J, Hollenberg CP, Gellissen G, Strasser AW. Two novel gene expression systems based on the yeasts Schwanniomyces occidentalis and Pichia stipitis. Appl Microbiol Biotechnol. 1998;50(3) 331-338.

[31] Schwarz WH, Gräbnitz F, Staudenbauer WL. Properties of a Clostridium thermocellum endoglucanase produced in Escherichia coli. Appl Environ Microbiol. 1986;51(6) 12931299.

[32] Shimoda C, Itadani A, Sugino A, Furusawa M. Isolation of thermotolerant mutants by using proofreading-deficient DNA polymerase delta as an effective mutator in Saccharomyces cerevisiae. Genes Genet Syst. 2006;81(6) 391-397.

[33] Sridhar M, Sree NK, Rao LV. Effect of UV radiation on thermotolerance, ethanol tolerance and osmotolerance of Saccharomyces cerevisiae VS1 and VS3 strains. Bioresour Technol. 2002;83(3) 199-202. 
[34] Ballesteros M, Oliva JM, Negro MJ, Manzanares P, Ballesteros I. Ethanol from lignocellulosic materials by a simultaneous saccharification and fermentation process (SFS) with Kluyveromyces marxianus CECT10875. Process Biochem. 2004;39 1843-1848.

[35] Boyle M, Barron N, McHale AP. Simultaneous saccharification and fermentation of straw to ethanol using the thermotolerant yeast strain Kluyveromyces marxianus imb3. Biotechnol Lett. 1997;19 49-51.

[36] Krishna S, Reddy T, Chowdary G. Simultaneous saccharification and fermentation of lignocellulosic wastes to ethanol using a thermotolerant yeast. Bioresour Technol. 2001;77 193-196.

[37] Lark N, Xia YK, Qin CG, Gong CS, Tsao GT. Production of ethanol from recycled paper sludge using cellulase and yeast, Kluveromyces marxianus. Biomass Bioenerg. 1997;12 135-143.

[38] Hong J, Wang Y, Kumagai H, Tamaki H. Construction of thermotolerant yeast expressing thermostable cellulase genes. J Biotechnol. 2007;130(2) 114-123.

[39] Hisamatsu M, Furubayashi T, Shuichi K, Takashi M, Naoto I. Isolation and identification of a novel yeast fermenting ethanol under acidic conditions. J Appl Glycosci 2006;53(2) 111-113.

[40] Kitagawa T, Tokuhiro K, Sugiyama H, Kohda K, Isono N, Hisamatsu M, Takahashi H, Imaeda T. Construction of a beta-glucosidase expression system using the multistresstolerant yeast Issatchenkia orientalis. Appl Microbiol Biotechnol. 2010;87(5) 1841-1853.

[41] Ingram LO, Conway T, Clark DP, Sewell GW, Preston JF. Genetic engineering of ethanol production in Escherichia coli. Appl Environ Microbiol. 1987;53(10) 2420-2425.

[42] Wood BE, Ingram LO. Ethanol production from cellobiose, amorphous cellulose, and crystalline cellulose by recombinant Klebsiella oxytoca containing chromosomally integrated Zymomonas mobilis genes for ethanol production and plasmids expressing thermostable cellulase genes from Clostridium thermocellum. Appl Environ Microbiol. 1992;58(7) 2103-2110.

[43] Doran JB, Aldrich HC, Ingram LO. Saccharification and fermentation of Sugar Cane bagasse by Klebsiella oxytoca P2 containing chromosomally integrated genes encoding the Zymomonas mobilis ethanol pathway. Biotechnol Bioeng. 1994;44(2) 240-247.

[44] Wood BE, Beall DS, Ingram LO. Production of recombinant bacterial endoglucanase as a co-product with ethanol during fermentation using derivatives of Escherichia coli KO11. Biotechnol Bioeng. 1997;55(3) 547-555.

[45] Zhou S, Ingram L. Engineering endoglucanase-secreting strains of ethanologenic Klebsiella oxytoca P2. J Ind Microbiol Biotechnol. 1999;22(6) 600-607.

[46] Zhou S, Davis FC, Ingram LO. Gene integration and expression and extracellular secretion of Erwinia chrysanthemi endoglucanase CelY (celY) and CelZ (celZ) in ethanologenic Klebsiella oxytoca P2. Appl Environ Microbiol. 2001;67(1) 6-14.

[47] Zhou S, Ingram L. Simultaneous saccharification and fermentation of amorphous cellulose to ethanol by recombinant Klebsiella oxytoca SZ21 without supplemental cellulase. Biotechnol Lett. 2001;23 1455-1462. 
[48] Bokinsky G, Peralta-Yahya PP, George A, Holmes BM, Steen EJ, Dietrich J, et al. Synthesis of three advanced biofuels from ionic liquid-pretreated switchgrass using engineered Escherichia coli. Proc Natl Acad Sci U S A. 2011;108(50) 19949-19954.

[49] Lee KJ, E. TD, L. RP. Ethanol production by Zymomonas mobilis in continuous culture at high glucose concentrations. Biotechnol Lett. 1979;1 421-426.

[50] Rogers PL, J. LK, E. TD. Kinetics of alcohol production by Zymomonas mobilis at high sugar concentrations. Biotechnology Letters. 1979;1 165-170.

[51] Lee KJ, Lefebvre M, Tribe DE, Rogers PL. High productivity ethanol fermentations with Zymomonas mobilis using continuous cell recycle. Biotechnol Lett. 1980;2 487-492.

[52] Lee KJ, Skotnicki ML, Tribe DE, Rogers PL. Kinetic studies on a highly productive strain of Zymomonas mobilis. Biotechnol Lett. 1980;2 339-344.

[53] Rogers PL, Lee KJ, Tribe DE. High productivity ethanol fermentations with Zymomonas mobilis. Process Biochem. 1980;15 7-11.

[54] Skotnicki ML, Lee KJ, Tribe DE, Rogers PL. Comparison of ethanol production by different zymomonas strains. Appl Environ Microbiol. 1981;41(4) 889-893.

[55] Yanase H, Nozaki K, Okamoto K. Ethanol production from cellulosic materials by genetically engineered Zymomonas mobilis. Biotechnol Lett. 2005;27(4) 259-263.

[56] Brestic-Goachet N, Gunasekaran P, Cami B, Baratti JC. Transfer and expression of an Erwinia chrysanthemi cellulase gene in Zymomonas mobilis. J Gen Microbiol. 1989;135 893902.

[57] Lejeune A, Eveleigh DE, Colson C. Expression of an endoglucanase gene of Pseudomonas fluorescens var. cellulosa in Zymomonas mobilis. FEMS Microbiol Lett. 1988;49 363-366.

[58] Misawa N, Okamoto T, Nakamura K. Expression of a cellulase gene in Zymomonas mobilis. J Biotechnol. 1988;7 167-178.

[59] Linger JG, Adney WS, Darzins A. Heterologous expression and extracellular secretion of cellulolytic enzymes by Zymomonas mobilis. Appl Environ Microbiol. 2010;76(19) 6360-6369.

[60] Rajnish KN, Choudhary GM, Gunasekaran P. Functional characterization of a putative endoglucanase gene in the genome of Zymomonas mobilis. Biotechnol Lett. 2008;30(8) 1461-1467.

[61] Ni Y, Sun Z. Recent progress on industrial fermentative production of acetone-butanolethanol by Clostridium acetobutylicum in China. Appl Microbiol Biotechnol. 2009;83(3) 415-423.

[62] Ali MK, Rudolph FB, Bennett GN. Characterization of thermostable Xyn10A enzyme from mesophilic Clostridium acetobutylicum ATCC 824. J Ind Microbiol Biotechnol. 2005;32(1) 12-18.

[63] Lee SF, Forsberg CW, Gibbins LN. Xylanolytic Activity of Clostridium acetobutylicum. Appl Environ Microbiol. 1985;50(4) 1068-1076.

[64] Nolling J, Breton G, Omelchenko MV, Makarova KS, Zeng Q, Gibson R, Lee HM, Dubois J, Qiu D, Hitti J, Wolf YI, Tatusov RL, Sabathe F, Doucette-Stamm L, Soucaille P, Daly MJ, Bennett GM, Koonin EV, Smith DR. Genome sequence and comparative analysis of the solvent-producing bacterium Clostridium acetobutylicum. J Bacteriol. 2001;183(16) 4823-4838. 
[65] Lopez-Contreras AM, Martens AA, Szijarto N, Mooibroek H, Claassen PA, van der Oost J, De Vos WM. Production by Clostridium acetobutylicum ATCC 824 of CelG, a cellulosomal glycoside hydrolase belonging to family 9. Appl Environ Microbiol. 2003;69(2) 869-877.

[66] Lopez-Contreras AM, Gabor K, Martens AA, Renckens BA, Claassen PA, Van Der Oost J, De Vos WM. Substrate-induced production and secretion of cellulases by Clostridium acetobutylicum. Appl Environ Microbiol. 2004;70(9) 5238-5243.

[67] Kim AY, Attwood GT, Holt SM, White BA, Blaschek HP. Heterologous expression of endo-beta-1,4-D-glucanase from Clostridium cellulovorans in Clostridium acetobutylicum ATCC 824 following transformation of the engB gene. Appl Environ Microbiol. 1994;60(1) 337-340.

[68] Mingardon F, Chanal A, Tardif C, Fierobe HP. The issue of secretion in heterologous expression of Clostridium cellulolyticum cellulase-encoding genes in Clostridium acetobutylicum ATCC 824. Appl Environ Microbiol. 2011;77(9) 2831-2838.

[69] Chanal A, Mingardon F, Bauzan M, Tardif C, Fierobe HP. Scaffoldin modules serving as "cargo" domains to promote the secretion of heterologous cellulosomal cellulases by Clostridium acetobutylicum. Appl Environ Microbiol. 2011;77(17) 6277-6280.

[70] Lopez-Contreras AM, Smidt H, van der Oost J, Claassen PA, Mooibroek H, de Vos WM. Clostridium beijerinckii cells expressing Neocallimastix patriciarum glycoside hydrolases show enhanced lichenan utilization and solvent production. Appl Environ Microbiol. 2001;67(11) 5127-5133.

[71] Bates EE, Gilbert HJ, Hazlewood GP, Huckle J, Laurie JI, Mann SP. Expression of a Clostridium thermocellum endoglucanase gene in Lactobacillus plantarum. Appl Environ Microbiol. 1989;55(8) 2095-2097.

[72] Scheirlinck T, Mahillon J, Joos H, Dhaese P, Michiels F. Integration and expression of alpha-amylase and endoglucanase genes in the Lactobacillus plantarum chromosome. Appl Environ Microbiol. 1989;55(9) 2130-2137.

[73] Rossi F, Rudella A, Marzotto M, Dellaglio F. Vector-free cloning of a bacterial endo-1,4beta-glucanase in Lactobacillus plantarum and its effect on the acidifying activity in silage: use of recombinant cellulolytic Lactobacillus plantarum as silage inoculant. Antonie Van Leeuwenhoek. 2001;80(2) 139-147.

[74] Ozkose E, Akyol I, Kar B, Comlekcioglu U, Ekinci MS. Expression of fungal cellulase gene in Lactococcus lactis to construct novel recombinant silage inoculants. Folia Microbiol (Praha). 2009;54(4) 335-342.

[75] Cho JS, Choi YJ, Chung DK. Expression of Clostridium thermocellum endoglucanase gene in Lactobacillus gasseri and Lactobacillus johnsonii and characterization of the genetically modified probiotic lactobacilli. Curr Microbiol. 2000;40(4) 257-263.

[76] Okano K, Zhang Q, Yoshida S, Tanaka T, Ogino C, Fukuda H, et al. D-lactic acid production from cellooligosaccharides and beta-glucan using L-LDH gene-deficient and endoglucanase-secreting Lactobacillus plantarum. Appl Microbiol Biotechnol. 2010;85(3) 643-650.

[77] Pernilla Turner GM, Eva N Karlsson. Potential and utilization of thermophiles and thermostable enzymes in biorefining. Microb Cell Fact. 2012;6(1) 9. 
htpp://www.microbialcellfactories.com/content/6/1/9

[78] Mai V, Wiegel J. Advances in development of a genetic system for Thermoanaerobacterium spp.: expression of genes encoding hydrolytic enzymes, development of a second shuttle vector, and integration of genes into the chromosome. Appl Environ Microbiol. 2000;66(11) 4817-4821.

[79] Adrio JL, Demain AL. Fungal biotechnology. Int Microbiol. 2003;6(3) 191-199.

[80] Schuster A, Schmoll M. Biology and biotechnology of Trichoderma. Appl Microbiol Biotechnol. 2010;87(3) 787-799.

[81] Miettinen-Oinonen A, Suominen P. Enhanced production of Trichoderma reesei endoglucanases and use of the new cellulase preparations in producing the stonewashed effect on denim fabric. Appl Environ Microbiol. 2002;68(8) 3956-3964.

[82] Miettinen-Oinonen A, Paloheimo M, Lantto R, Suominen P. Enhanced production of cellobiohydrolases in Trichoderma reesei and evaluation of the new preparations in biofinishing of cotton. J Biotechnol. 2005;116(3) 305-317.

[83] Bower B, Larenas E, Mitchenson C. Inventors; Exo-endo cellulase fusion protein 2005. US Patent WO2005093073

[84] Li D-C, Li A-N, Papageorgiou AC. Cellulases from thermophilic fungi: Recent insights and biotechnological potential. Enzyme Research. 2012;2011.

[85] Sandgren M, Stahlberg J, Mitchinson C. Structural and biochemical studies of GH family 12 cellulases: improved thermal stability, and ligand complexes. Prog Biophys Mol Biol. 2005;89(3) 246-291.

[86] Jeoh T, Michener W, Himmel ME, Decker SR, Adney WS. Implications of cellobiohydrolase glycosylation for use in biomass conversion. Biotechnol Biofuels. 2008;1(1) 10.

[87] Tambor JH, Ren H, Ushinsky S, Zheng Y, Riemens A, St-Francois C, et al. Recombinant expression, activity screening and functional characterization identifies three novel endo-1,4-beta-glucanases that efficiently hydrolyse cellulosic substrates. Appl Microbiol Biotechnol. 2012;93(1) 203-214.

[88] Zhang YH, Lynd LR. Toward an aggregated understanding of enzymatic hydrolysis of cellulose: noncomplexed cellulase systems. Biotechnol Bioeng. 2004;88(7) 797-824.

[89] Lynd LR, Weimer PJ, van Zyl WH, Pretorius IS. Microbial cellulose utilization: fundamentals and biotechnology. Microbiol Mol Biol Rev. 2002;66(3) 506-577,

[90] Gerngross UT, Romaniec MP, Kobayashi T, Huskisson NS, Demain AL. Sequencing of a Clostridium thermocellum gene (cipA) encoding the cellulosomal SL-protein reveals an unusual degree of internal homology. Mol Microbiol. 1993;8(2) 325-334.

[91] Fierobe HP, Mingardon F, Mechaly A, Belaich A, Rincon MT, Pages S, et al. Action of designer cellulosomes on homogeneous versus complex substrates: controlled incorporation of three distinct enzymes into a defined trifunctional scaffoldin. J Biol Chem. 2005;280(16) 16325-16334.

[92] Mingardon F, Chanal A, Tardif C, Bayer EA, Fierobe HP. Exploration of new geometries in cellulosome-like chimeras. Appl Environ Microbiol. 2007;73(22):71387149 . 
[93] Perret S, Casalot L, Fierobe HP, Tardif C, Sabathe F, Belaich JP, et al. Production of heterologous and chimeric scaffoldins by Clostridium acetobutylicum ATCC 824. J Bacteriol. 2004;186(1) 253-257.

[94] Wen F, Sun J, Zhao H. Yeast surface display of trifunctional minicellulosomes for simultaneous saccharification and fermentation of cellulose to ethanol. Appl Environ Microbiol. 2010 76(4) 1251-1260.

[95] Kruus K, Lua AC, Demain AL, Wu JH. The anchorage function of CipA (CelL), a scaffolding protein of the Clostridium thermocellum cellulosome. Proc Natl Acad Sci U S A. 1995;92(20) 9254-9258.

[96] Leibovitz E, Beguin P. A new type of cohesin domain that specifically binds the dockerin domain of the Clostridium thermocellum cellulosome-integrating protein CipA. J Bacteriol. 1996;178(11) 3077-3084.

[97] Lemaire M, Ohayon H, Gounon P, Fujino T, Beguin P. OlpB, a new outer layer protein of Clostridium thermocellum, and binding of its S-layer-like domains to components of the cell envelope. J Bacteriol. 1995;177(9) 2451-2459.

[98] Kataeva I, Guglielmi G, Beguin P. Interaction between Clostridium thermocellum endoglucanase CelD and polypeptides derived from the cellulosome-integrating protein CipA: stoichiometry and cellulolytic activity of the complexes. Biochem J. 1997;326(2):617-624.

[99] Ciruela A, Gilbert HJ, Ali BR, Hazlewood GP. Synergistic interaction of the cellulosome integrating protein (CipA) from Clostridium thermocellum with a cellulosomal endoglucanase. FEBS Lett. 1998;422(2) 221-224.

[100] Murashima K, Kosugi A, Doi RH. Synergistic effects on crystalline cellulose degradation between cellulosomal cellulases from Clostridium cellulovorans. J Bacteriol. 2002;184(18) 5088-5095.

[101] Fierobe HP, Mechaly A, Tardif C, Belaich A, Lamed R, Shoham Y, Belaich JP, Bayer EA. Design and production of active cellulosome chimeras. Selective incorporation of dockerin-containing enzymes into defined functional complexes. J Biol Chem. 2001;276(24) 21257-21261.

[102] Fierobe HP, Bayer EA, Tardif C, Czjzek M, Mechaly A, Belaich A, et al. Degradation of cellulose substrates by cellulosome chimeras. Substrate targeting versus proximity of enzyme components. J Biol Chem. 2002;277(51) 49621-49630.

[103] Morais S, Barak Y, Caspi J, Hadar Y, Lamed R, Shoham Y, et al. Contribution of a xylan-binding module to the degradation of a complex cellulosic substrate by designer cellulosomes. Appl Environ Microbiol. 2010;76(12) 3787-3796.

[104] Morais S, Barak Y, Caspi J, Hadar Y, Lamed R, Shoham Y, et al. Cellulase-xylanase synergy in designer cellulosomes for enhanced degradation of a complex cellulosic substrate. MBio. 2010;1(5) doi:10.1128.

[105] Murashima K, Chen CL, Kosugi A, Tamaru Y, Doi RH, Wong SL. Heterologous production of Clostridium cellulovorans engB, using protease-deficient Bacillus subtilis, and preparation of active recombinant cellulosomes. J Bacteriol. 2002;184(1) 76-81. 
[106] Cho HY, Yukawa H, Inui M, Doi RH, Wong SL. Production of minicellulosomes from Clostridium cellulovorans in Bacillus subtilis WB800. Appl Environ Microbiol. 2004;70(9) 5704-5707.

[107] Arai T, Matsuoka S, Cho HY, Yukawa H, Inui M, Wong SL, et al. Synthesis of Clostridium cellulovorans minicellulosomes by intercellular complementation. Proc Natl Acad Sci U S A. 2007;104(5) 1456-1460.

[108] Sabathe F, Belaich A, Soucaille P. Characterization of the cellulolytic complex cellulosome) of Clostridium acetobutylicum. FEMS Microbiol Lett. 2002;217(1) 15-22.

[109] Sabathe F, Soucaille P. Characterization of the CipA scaffolding protein and in vivo production of a minicellulosome in Clostridium acetobutylicum. J Bacteriol. 2003;185(3) 1092-1096.

[110] Kosugi A, Amano Y, Murashima K, Doi RH. Hydrophilic domains of scaffolding protein $\mathrm{CbpA}$ promote glycosyl hydrolase activity and localization of cellulosomes to he cell surface of Clostridium cellulovorans. J Bacteriol. 2004;186(19) 6351-6359.

[111] Garcia-Campayo V, Beguin P. Synergism between the cellulosome-integrating protein CipA and endoglucanase CelD of Clostridium thermocellum. J Biotechnol. 1997;57(1-3) 3947.

[112] Zverlov VV, Klupp M, Krauss J, Schwarz WH. Mutations in the scaffoldin gene, cipA, of Clostridium thermocellum with impaired cellulosome formation and cellulose hydrolysis: insertions of a new transposable element, IS1447, and implications for cellulase synergism on crystalline cellulose. J Bacteriol. 2008;190(12) 4321-4327.

[113] Lynd LR, van Zyl WH, McBride JE, Laser M. Consolidated bioprocessing of cellulosic biomass: an update. Curr Opin Biotechnol. 2005;16(5) 577-583.

[114] Lu Y, Zhang YH, Lynd LR. Enzyme-microbe synergy during cellulose hydrolysis by Clostridium thermocellum. Proc Natl Acad Sci U S A. 2006;103(44) 16165-16169.

[115] Miron J, Ben-Ghedalia D, Morrison M. Invited review: adhesion mechanisms of rumen cellulolytic bacteria. J Dairy Sci. 2001;84(6) 1294-1309.

[116] Schwarz WH. The cellulosome and cellulose degradation by anaerobic bacteria. Appl Microbiol Biotechnol. 2001;56(5-6) 634-649.

[117] Bayer EA, Kenig R, Lamed R. Adherence of Clostridium thermocellum to cellulose. J Bacteriol. 1983;156(2) 818-827.

[118] Ng TK, Weimer TK, Zeikus JG. Cellulolytic and physiological properties of Clostridium hermocellum. Arch Microbiol. 1977;114(1) 1-7.

[119] Lilly M, Fierobe HP, van Zyl WH, Volschenk H. Heterologous expression of a Clostridium minicellulosome in Saccharomyces cerevisiae. FEMS Yeast Res. 2009;9(8) 1236-1249.

[120] Ito J, Kosugi A, Tanaka T, Kuroda K, Shibasaki S, Ogino C, et al. Regulation of the display ratio of enzymes on the Saccharomyces cerevisiae cell surface by the mmunoglobulin $\mathrm{G}$ and cellulosomal enzyme binding domains. Appl Environ Microbiol. 2009;75(12) 4149-4154.

[121] Tsai SL, Oh J, Singh S, Chen R, Chen W. Functional assembly of minicellulosomes on he Saccharomyces cerevisiae cell surface for cellulose hydrolysis and ethanol production. Appl Environ Microbiol. 2009;75(19) 6087-6093. 
[122] Tsai SL, Goyal G, Chen W. Surface display of a functional minicellulosome by ntracellular complementation using a synthetic yeast consortium and its application to cellulose hydrolysis and ethanol production. Appl Environ Microbiol. 2010;76(22) 75147520 .

[123] Wieczorek AS, Martin VJ. Engineering the cell surface display of cohesins for assembly of cellulosome-inspired enzyme complexes on Lactococcus lactis. Microb Cell Fact. 2010 9:69. http://www.microbialcellfactories.com/content/9/1/69

[124] Anderson TD, Robson SA, Jiang XW, Malmirchegini GR, Fierobe HP, Lazazzera BA, et al. Assembly of minicellulosomes on the surface of Bacillus subtilis. Appl Environ Microbiol. 2011;77(14) 4849-4858.

[125] You C, Zhang XZ, Sathitsuksanoh N, Lynd LR, Zhang YH. Enhanced microbial utilization of recalcitrant cellulose by an ex vivo cellulosome-microbe complex. Appl Environ Microbiol. 2012;78(5):1437-1444. 